Supporting Information for

\title{
Theoretical Study on Singlet Fission in Aromatic Diaza s- Indacene Dimers
}

Takanori Nagami, ${ }^{\dagger}$ Ryota Sugimori, ${ }^{\dagger}$ Ryota Sakai, ${ }^{\dagger}$ Kenji Okada, ${ }^{\dagger}$ and Masayoshi Nakano $*, \dagger, \downarrow, \S, \|, \oplus$

\footnotetext{
${ }^{\dagger}$ Department of Materials Engineering Science, Graduate School of Engineering Science, Osaka University, Toyonaka, Osaka 560-8531, Japan

¥ Research Center for Solar Energy Chemistry (RCSEC), Osaka University, Toyonaka, Osaka 560-8531, Japan

$\S$ Center for Quantum Information and Quantum Biology Division (QIQB), Institute for International Advanced Research Institute (IARI), Osaka University, Toyonaka, Osaka 560-8531, Japan

" Innovative Catalysis Science Division (ICS), Institute for Open and Transdisciplinary Research Initiatives (OTRI), Osaka University, Toyonaka, Osaka 560-8531, Japan

" Center for Spintronics Research Network (CSRN), Graduate School of Engineering Science, Osaka University, Toyonaka, Osaka 560-8531, Japan
} 


\section{Contents}

1. Charge distributions of $\mathrm{N}_{2}-S$-indacenes (Figure S1)

2. Calculated VCI parameters of $\mathrm{N}_{2}-S$-indacenes (Table S1, Figure S2)

3. HOMO and LUMO distributions of A-1 and A-3 (Figure S3)

4. Electronic coupling matrix elements (Figure S4, Figure S5)

5. Charge-transfer energy (Figure S6)

6. Dimer packings for A-2 and A-4 (Figure S7, Figure S8)

7. Aromaticity for the $4 n \pi$ analogues of $N_{2}-S$-indacenes (Figure S9)

8. Cartesian coordinates of $\mathrm{N}_{2}-S$-indacenes 


\section{Charge distributions of $\mathbf{N}_{2}$-s-indacenes}

(a)

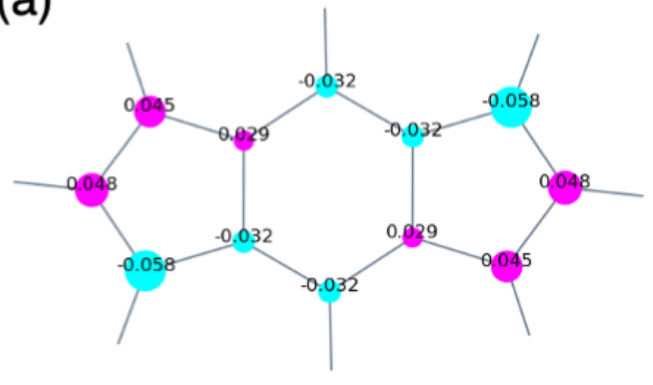

(c)

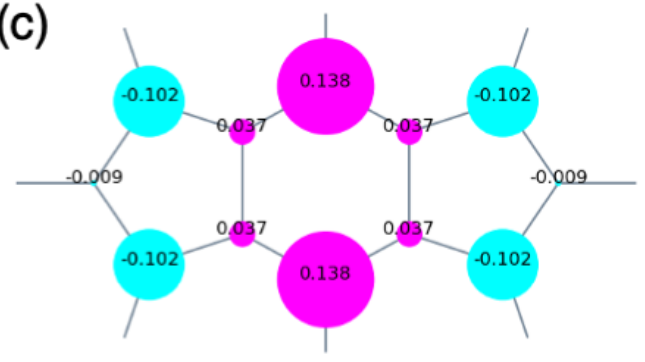

(b)

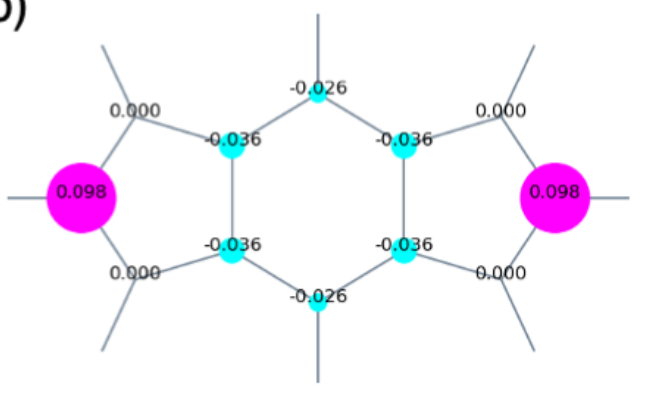

(d)

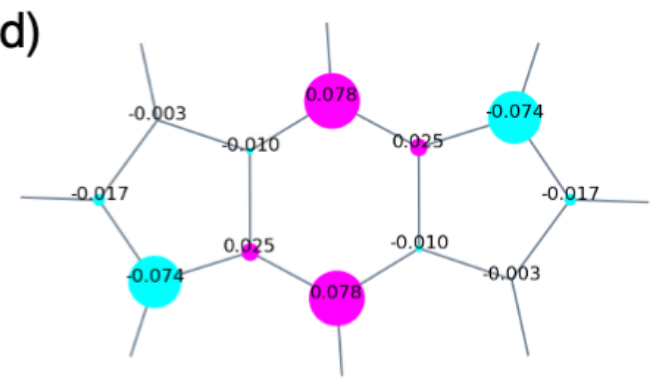

Figure S1. Hirshfeld charge (summed into heavy atom) distributions of $\mathrm{N}_{2}$-S-indacenes in the ground states for A-1 (a), A-2 (b), A-3 (c), and A-4 (d). Magenta and cyan circles denote positive and negative charges, respectively. The radius of the circle on each heavy atom is proportional to the magnitude of each atomic charge. 


\section{Calculated VCI parameters of $\mathbf{N}_{2}-s$-indacenes}

Table S1. VCI Parameters Obtained from CASCI(2,2)/cc-pVDZ Calculations for $\mathrm{N}_{2}-S-$ Indacenes.

\begin{tabular}{cccccccccc}
\hline Molecule & $y_{0}{ }^{a}$ & $U^{b}$ & $\left|t_{a b}\right|^{b}$ & $E\left(\mathrm{~S}_{1}\right)^{b}$ & $E\left(\mathrm{~T}_{1}\right)^{b}$ & $K_{a b}{ }^{b}$ & $f^{a}$ & $f_{1}\left(y_{0}\right)^{a}$ & $r_{K}{ }^{a}$ \\
\hline s-indacene & 0.007 & 0.021 & 0.045 & 0.077 & 0.056 & 0.012 & -1.662 & -2.769 & 1.108 \\
A-1 & 0.025 & 0.090 & 0.098 & 0.235 & 0.146 & 0.005 & -0.626 & -0.746 & 0.120 \\
A-2 & 0.105 & 0.106 & 0.053 & 0.162 & 0.056 & 0.005 & 0.467 & 0.379 & 0.088 \\
A-3 & 0.014 & 0.039 & 0.058 & 0.102 & 0.063 & 0.018 & -0.605 & -1.522 & 0.917 \\
A-4 & 0.052 & 0.081 & 0.060 & 0.140 & 0.058 & 0.014 & 0.284 & -0.066 & 0.349 \\
anthracene & 0.038 & 0.085 & 0.075 & 0.195 & 0.110 & 0.001 & -0.300 & -0.324 & 0.025 \\
\hline
\end{tabular}

${ }^{a}$ Dimensionless values. ${ }^{b}$ In atomic units. 
(a)

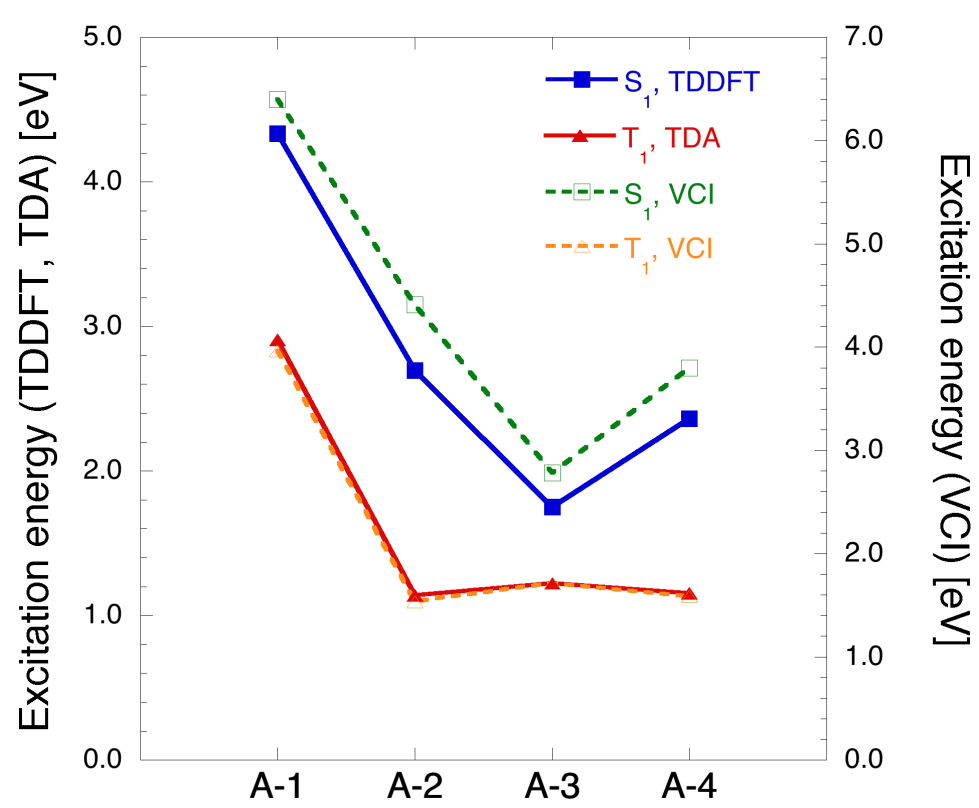

(b)

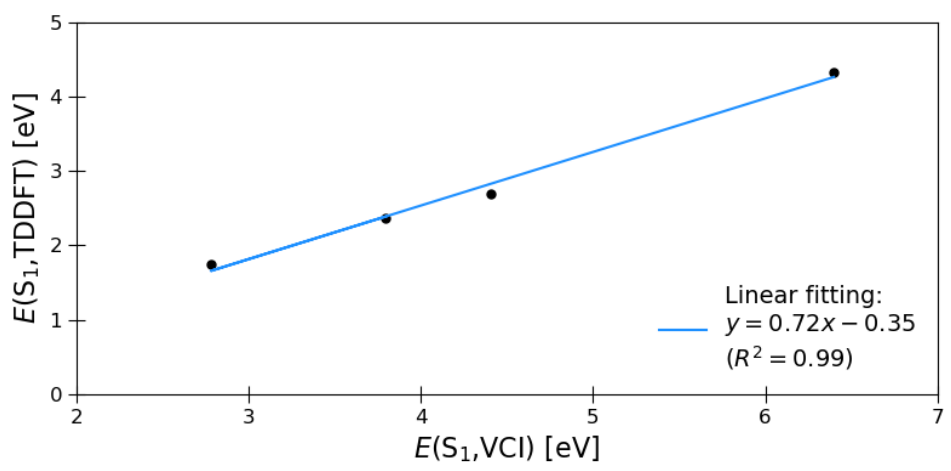

(c)

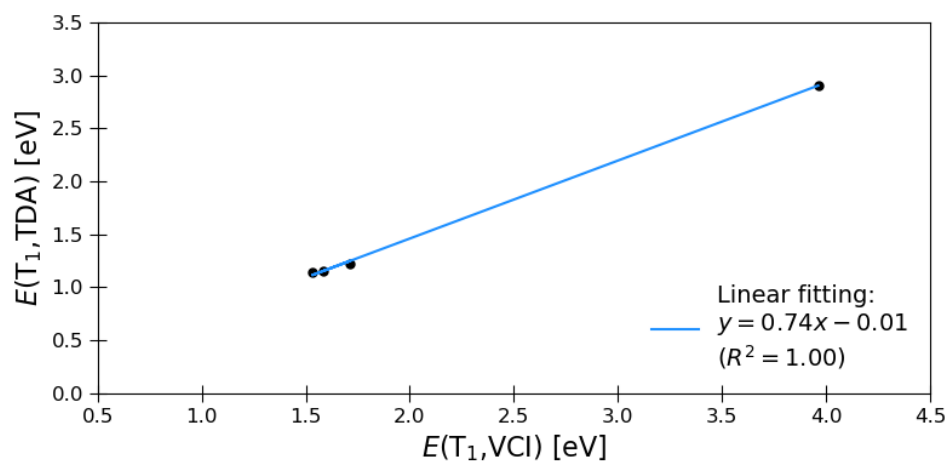

Figure S2. Comparison of excitation energies for $\mathrm{N}_{2}-s$-indacenes between the TDDFT and TDA results and VCI results. (a): TDDFT and TDA results are shown in solid lines with filled markers, while the $\mathrm{VCI}$ ones are in dashed lines with open markers. $\mathrm{S}_{1}$ and $\mathrm{T}_{1}$ energies are marked with square and triangle, respectively. Linear fittings are also given for $S_{1}(b)$ and $T_{1}(c)$ energies. 
According to the two-site VCI model, ${ }^{\text {s1,s2 }}$ the analytical expressions of excitation energies $\left[E\left(\mathrm{~S}_{1}\right)\right.$ and $\left.E\left(\mathrm{~T}_{1}\right)\right]$ for the two-electrons in two-orbital system are given as

$$
\begin{aligned}
& E\left(\mathrm{~S}_{1}\right)=\frac{U}{2}\left[1+\frac{1}{\sqrt{1-\left(1-y_{0}\right)^{2}}}\right]-2 K_{a b} \\
& E\left(\mathrm{~T}_{1}\right)=\frac{U}{2}\left[-1+\frac{1}{\sqrt{1-\left(1-y_{0}\right)^{2}}}\right]-2 K_{a b}
\end{aligned}
$$

where $y_{0}, U$, and $K_{a b}$ are the diradical character, the effective Coulomb repulsion, and the exchange integral in localized natural orbital basis, respectively. The diradical character $y_{0}$ is also given analytically as

$$
y_{0}=1-\frac{1}{\sqrt{1+\left(\frac{U}{4\left|t_{a b}\right|}\right)^{2}}}
$$

where $t_{a b}$ denotes the transfer integral between the localized sites. Using eqs S1 and S2, the dimensionless energy level matching condition is given by

$$
\begin{aligned}
f & \equiv \frac{E\left(\mathrm{~S}_{1}\right)-2 E\left(\mathrm{~T}_{1}\right)}{U} \\
& =\frac{1}{2}\left[3-\frac{1}{\sqrt{1-\left(1-y_{0}\right)^{2}}}\right]+\frac{2 K_{a b}}{U} \\
& =f_{1}\left(y_{0}\right)+r_{K}
\end{aligned}
$$

where $f_{1}\left(y_{0}\right)$ and $r_{K}$ denote the contribution from $y_{0}$ and $K_{a b}$ (and $U$ ), respectively.

Table S1 lists the parameters obtained from CASCI(2,2)/cc-pVDZ calculation (see the Computational Details section for more detail) for the molecules investigated, including $s$-indacene and anthracene. From the comparison of Table 1 and Table S1, it is found that $s$-indacene's $y_{0}$ value obtained from PUHF is the largest $\left[y_{0}(\mathrm{PUHF})=0.382\right.$, Table 1] while that from CASCI is the smallest $\left[y_{0}(\mathrm{CASCI})=0.007\right.$, Table S1] among all the molecules listed. This is because the VCI model for $s$-indacene is no longer valid, due to the considerable intrusion of other orbitals than HOMO and LUMO as mentioned in the Introduction. ${ }^{\mathrm{s} 3}$

As seen from Figure S2, the excitation energies from the VCI model are in good agreement with those from the TDDFT and TDA methods, especially for the $E\left(\mathrm{~T}_{1}\right)$ energies. As a result, $f$ values eq $\mathrm{S} 4$ given in Table $\mathrm{S} 1$ are found to reproduce semiquantitatively $\Delta \mathrm{sF}$ given in Table 1 , at least the signs of $f$ and $\Delta \mathrm{SF}$. 
Although one would notice that although $y_{0}(\mathrm{VCI})$ values correspond to $y_{0}(\mathrm{PUHF})$ values in $\mathbf{A - 2}$ and $\mathbf{A}-4\left[y_{0}(\mathrm{VCI})=0.105\right.$ (A-2) and 0.052 (A-4) vs. $y_{0}(\mathrm{PUHF})$ $=0.324(\mathbf{A}-2)$ and $0.241(\mathbf{A}-4)]$, they do not reflect the large/small relationship between A-1 and A-3, where $y_{0}(\mathrm{VCI})(=0.025)$ in $\mathbf{A - 1}$ is overestimated, while $y_{0}(\mathrm{VCI})$ in A-3 $(=0.014)$ is underestimated compared to $y_{0}(\mathrm{PUHF})[=0.019(\mathbf{A - 1})$ and $0.236(\mathbf{A - 4})]$. Although $y_{0}(\mathrm{VCI})$ and $y_{0}(\mathrm{PUHF})$ in the present $\mathbf{A - 1}$ and $\mathbf{A - 3}$ are somehow not in agreement with each other, the excitation energies obtained by scaling the VCI values agree well with the TDDFT and TDA values (see Figure S3) and therefore the VCI values are predicted to be, at least, reliable to analyze their origins, despite the fact that the VCI model is composed of only two-orbitals. In addition, $y_{0}(\mathrm{VCI})$ in $\mathbf{A - 2}$ and A-4, both of which are SF candidates, are found to reflect the feature of $y_{0}$ (PUHF), which guarantees the VCI analysis at least between A-2 and A-4. 


\section{HOMO and LUMO distributions of A-1 and A-3}

(a)

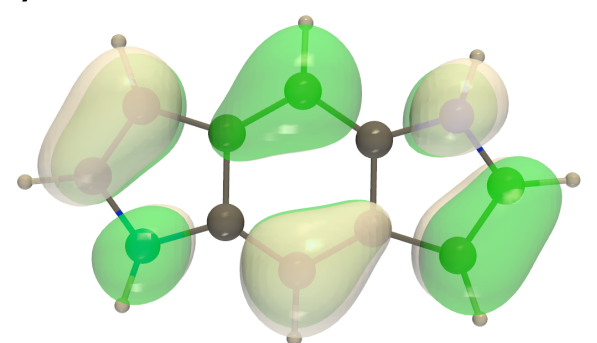

HOMO

(b)

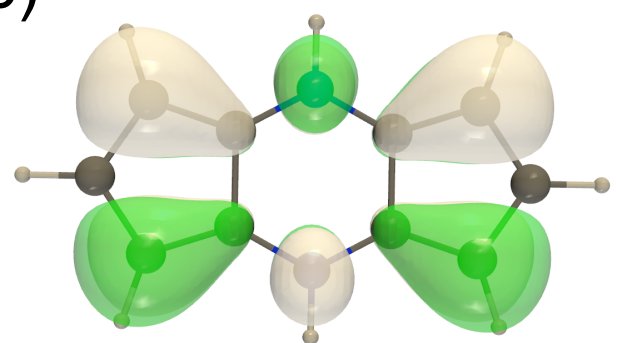

HOMO

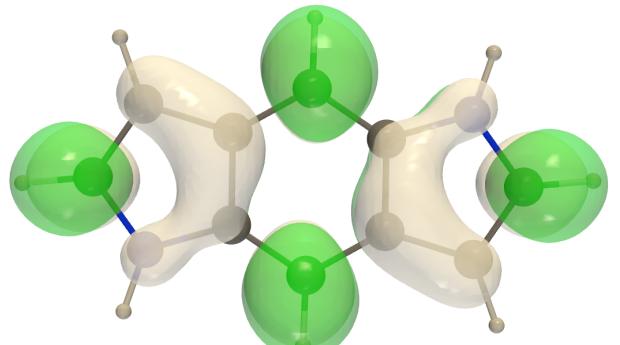

LUMO

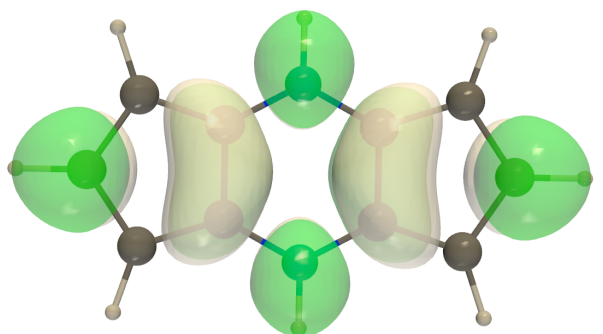

LUMO

Figure S3. HOMO and LUMO distributions of A-1 (a) and A-3 (b). White and green surfaces indicate the positive and negative phases with the contour value of \pm 0.03 a.u., respectively. 


\section{Electronic coupling matrix elements}

(a)

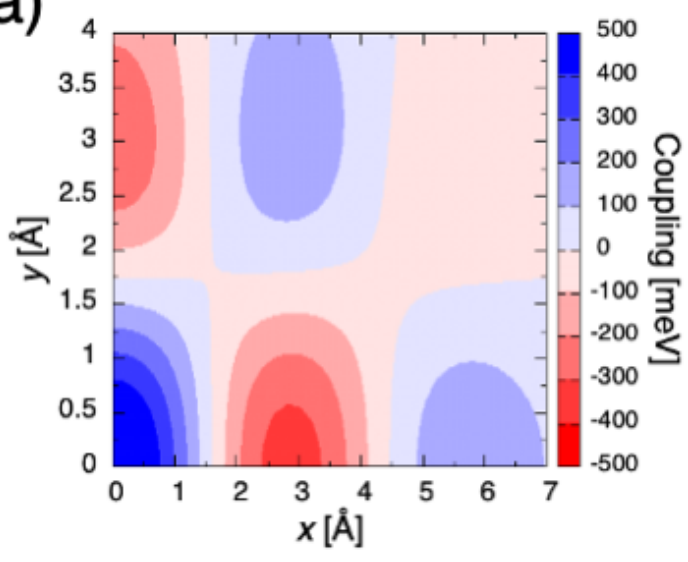

(c)

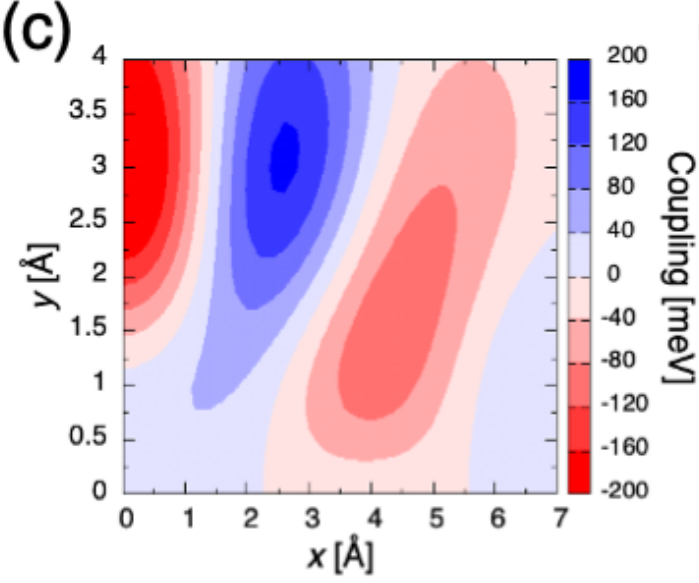

(b)

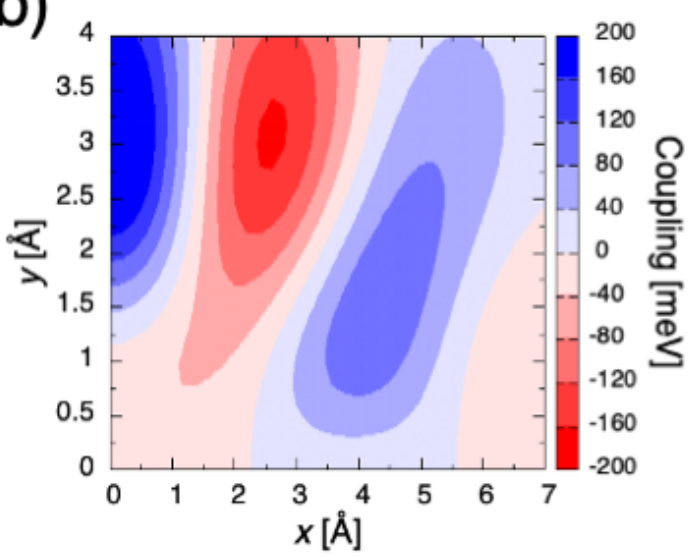

(d)

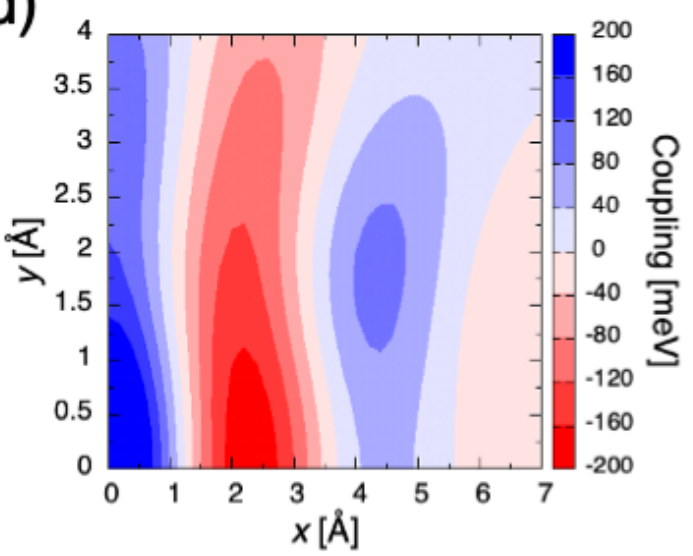

Figure S4. $\quad(x, y)$-Dependences of electronic coupling matrix elements for the slip-stack dimer model of A-2, $V_{\mathrm{HH}}(\mathrm{a}), V_{\mathrm{HL}}(\mathrm{b}), V_{\mathrm{LH}}(\mathrm{c})$, and $V_{\mathrm{LL}}(\mathrm{d})$. 
(a)

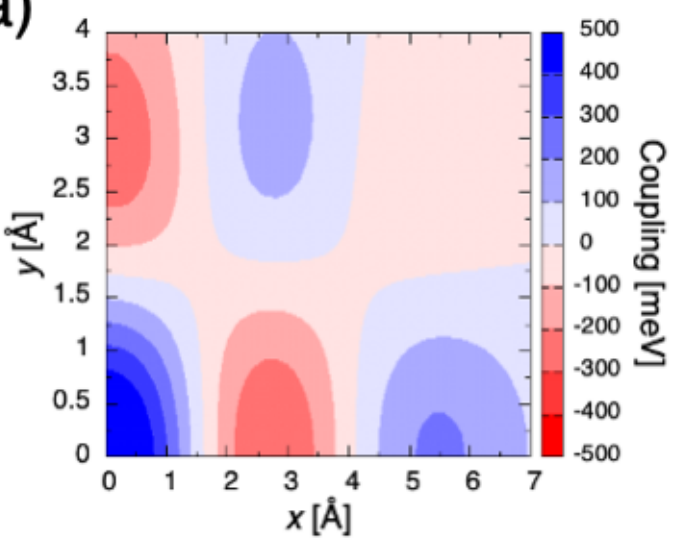

(c)

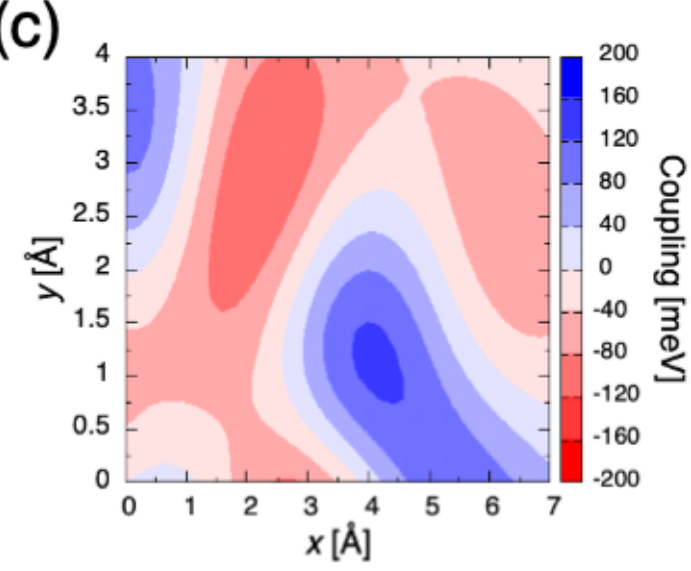

(b)

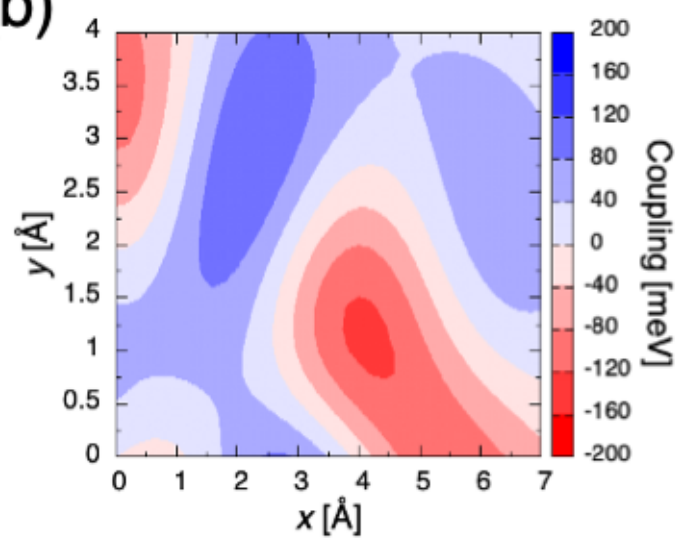

(d)

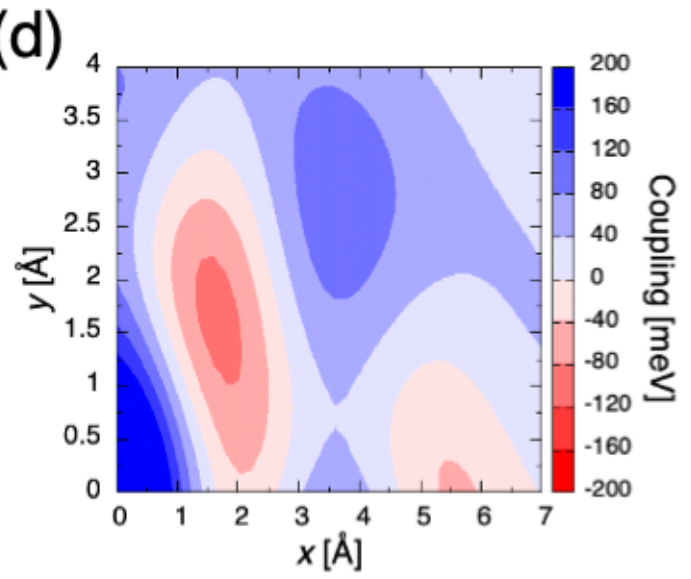

Figure S5. $\quad(x, y)$-Dependences of electronic coupling matrix elements for the slip-stack dimer model of A-4, $V_{\mathrm{HH}}(\mathrm{a}), V_{\mathrm{HL}}(\mathrm{b}), V_{\mathrm{LH}}(\mathrm{c})$, and $V_{\mathrm{LL}}(\mathrm{d})$. 


\section{Charge-transfer energy}

(a)

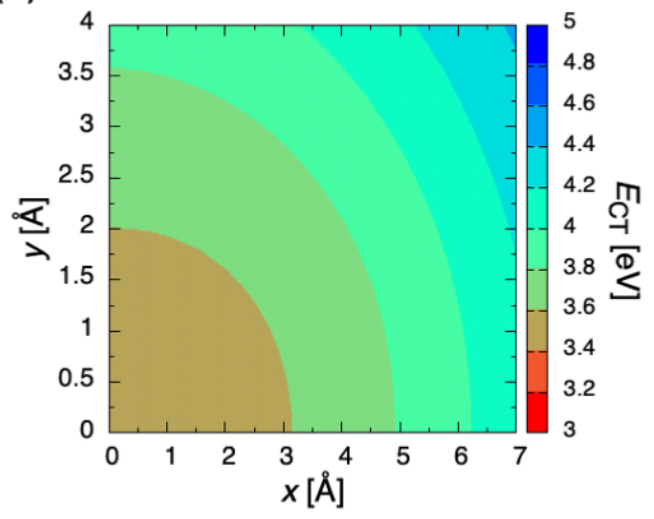

(b)

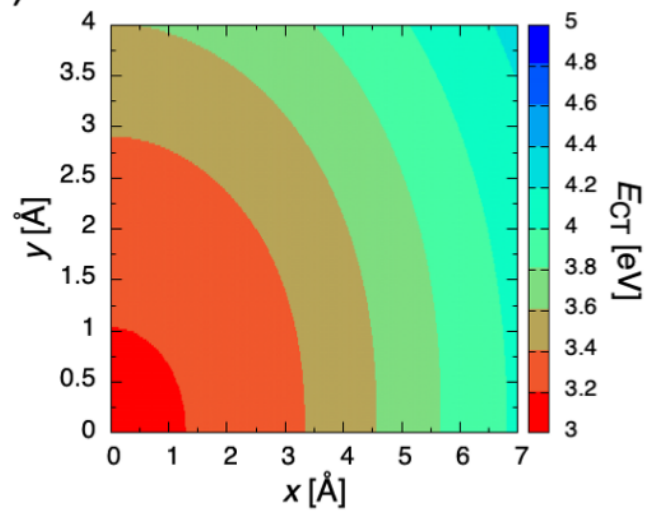

Figure S6. $(x, y)$-Dependences of charge-transfer energies for the slip-stack dimer models of A-2 (a) and A-4 (b). 


\section{Dimer packings for A-2 and A-4}
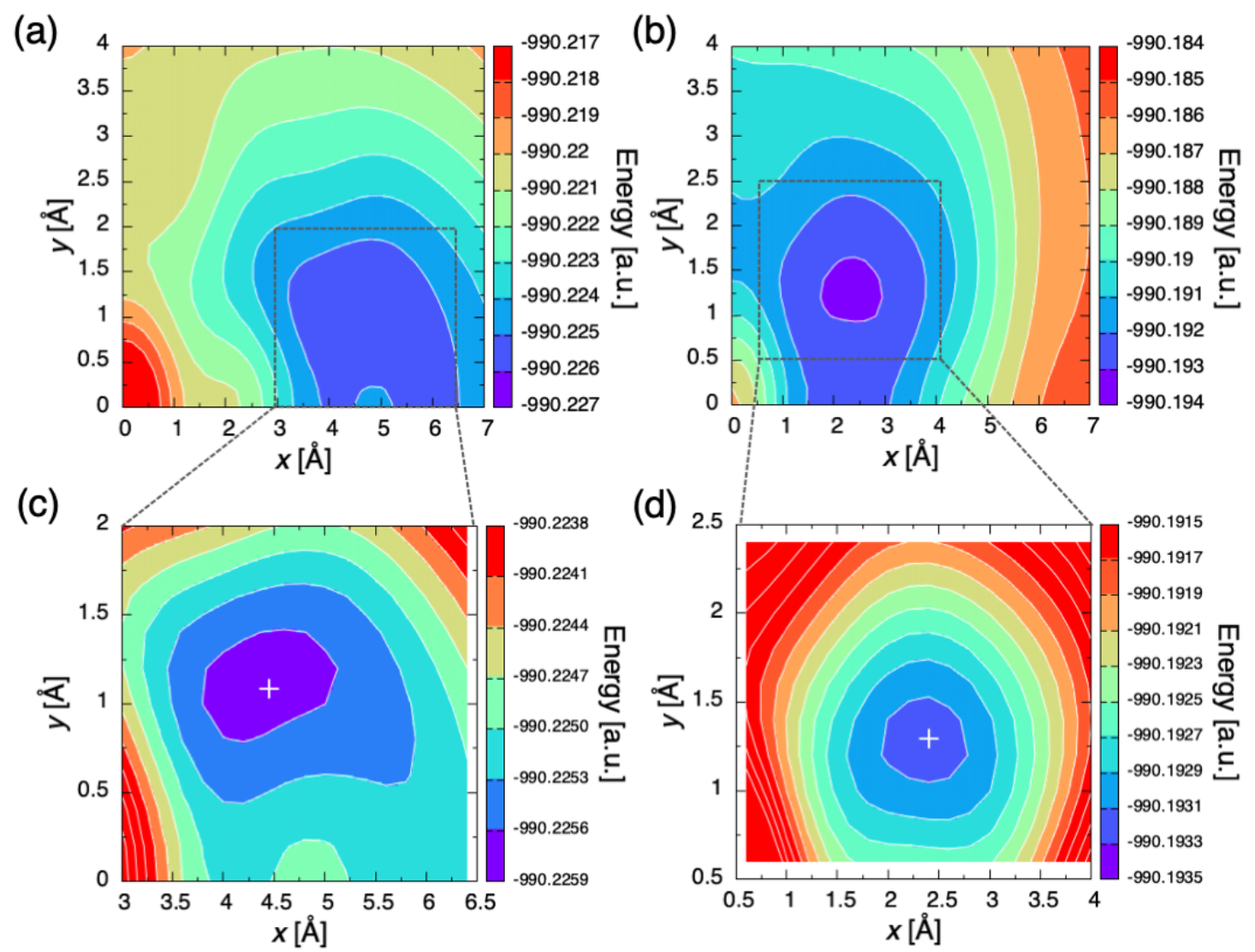

Figure S7. $(x, y)$-Dependences of dimer energies for A-2 (a) and A-4 (b), and their enlarged views for the bottoms for A-2 (c) and A-4 (d). The geometries yielding the energy minima are also shown (white "+" marker) in (c) and (d). 
(a) A-2 dimer $[(x, y)=(4.5 \AA, 1.1 \AA), z=3.6 \AA]$

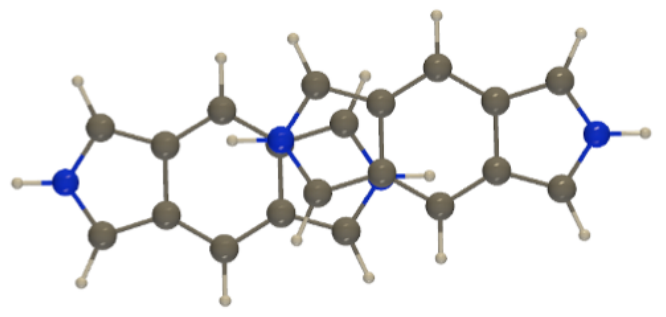

Top view

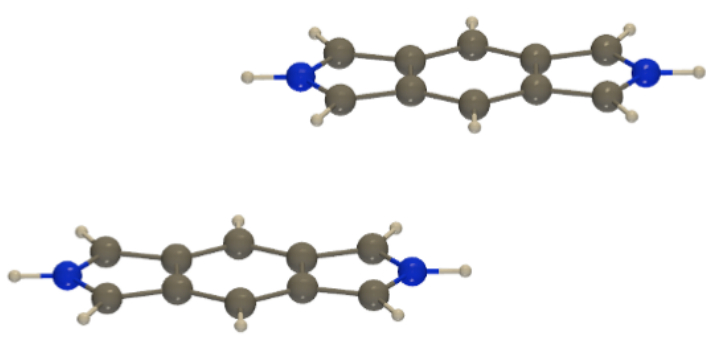

Side view

(b) A-4 dimer $[(x, y)=(2.4 \AA, 1.3 \AA), z=3.6 \AA]$

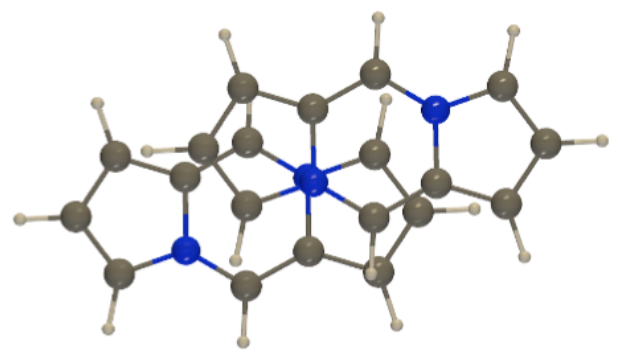

Top view

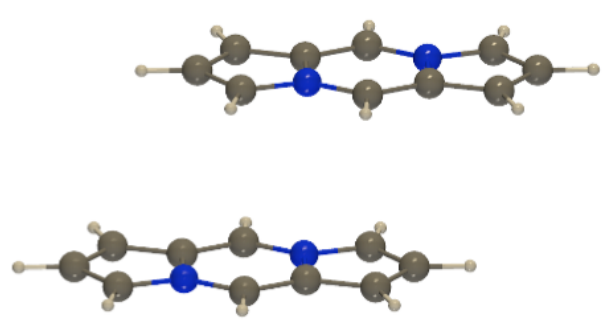

Side view

Figure S8. $\mathrm{N}_{2}-s$-indacenes dimer configurations yielding global energy minima of A2 (a) and A-4 (b) in the slip-stack dimer model. 
(a)<smiles>C1=Cc2cc3c(cc2=N1)C=CN=3</smiles>

B-1<smiles></smiles>

B-2<smiles>C1=Cc2nc3c(nc2=C1)C=CC=3</smiles>

B-3 (b)

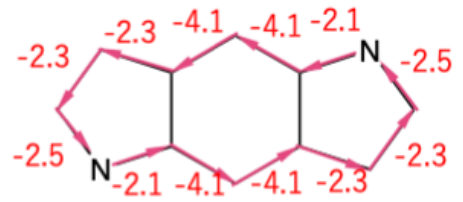

B-1

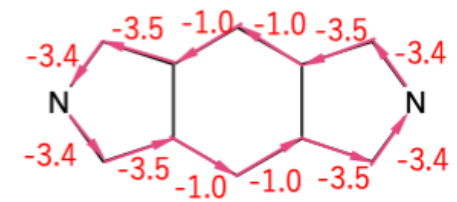

B-2

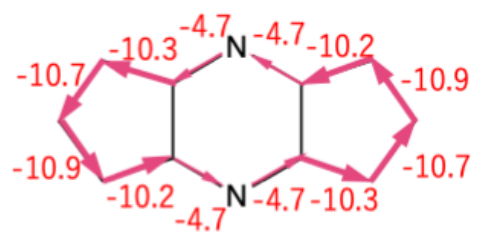

B-3

Figure S9. Chemical structures of $4 n \pi$-analogues of $\mathrm{N}_{2}-s$-indacenes as B-1, B-2, and B-3 (a) and calculated current strengthes for B-1, B-2, and B-3 (b). See the caption of Figure 7 for more details. 


\section{Cartesian coordinates of $\mathbf{N}_{\mathbf{2}}-\mathrm{S}$-indacenes}

The geometries are optimized at CAM-B3LYP/6-311G* level.

A-1

$\begin{array}{llll}\text { Atom } & \mathrm{x}[\AA] & \mathrm{y}[\AA] & \mathrm{z}[\AA] \\ \mathrm{C} & 0.000000 & -0.016774 & 3.324363 \\ \mathrm{C} & 0.000000 & 1.444624 & 0.021119 \\ \mathrm{H} & 0.000000 & 0.097945 & 4.405367 \\ \mathrm{H} & 0.000000 & 2.536039 & 0.045496 \\ \mathrm{C} & 0.000000 & 0.016774 & -3.324363 \\ \mathrm{C} & 0.000000 & -1.444624 & -0.021119 \\ \mathrm{H} & 0.000000 & -0.097945 & -4.405367 \\ \mathrm{H} & 0.000000 & -2.536039 & -0.045496 \\ \mathrm{C} & 0.000000 & 0.684772 & 1.184125 \\ \mathrm{~N} & 0.000000 & 1.090812 & 2.505689 \\ \mathrm{H} & 0.000000 & 2.048780 & 2.819673 \\ \mathrm{C} & 0.000000 & -0.744064 & 1.187687 \\ \mathrm{C} & 0.000000 & -1.153136 & 2.569234 \\ \mathrm{H} & 0.000000 & -2.171350 & 2.947645 \\ \mathrm{C} & 0.000000 & 0.744064 & -1.187687 \\ \mathrm{C} & 0.000000 & 1.153136 & -2.569234 \\ \mathrm{H} & 0.000000 & 2.171350 & -2.947645 \\ \mathrm{C} & 0.000000 & -0.684772 & -1.184125 \\ \mathrm{~N} & 0.000000 & -1.090812 & -2.505689 \\ \mathrm{H} & 0.000000 & -2.048780 & -2.819673\end{array}$

A-2

$\begin{array}{lllc}\text { Atom } & \mathrm{x}[\AA] & \mathrm{y}[\AA] & \mathrm{z}[\AA] \\ \mathrm{N} & 0.000000 & 0.000000 & 3.293426 \\ \mathrm{C} & 0.000000 & 1.453740 & 0.000000 \\ \mathrm{H} & 0.000000 & 0.000000 & 4.305053 \\ \mathrm{H} & 0.000000 & 2.545474 & 0.000000 \\ \mathrm{~N} & 0.000000 & 0.000000 & -3.293426\end{array}$




$\begin{array}{lrrr}\mathrm{C} & 0.000000 & -1.453740 & 0.000000 \\ \mathrm{H} & 0.000000 & 0.000000 & -4.305053 \\ \mathrm{H} & 0.000000 & -2.545474 & 0.000000 \\ \mathrm{C} & 0.000000 & 0.731197 & 1.196379 \\ \mathrm{C} & 0.000000 & 1.132588 & 2.545556 \\ \mathrm{H} & 0.000000 & 2.116650 & 3.001122 \\ \mathrm{C} & 0.000000 & -0.731197 & 1.196379 \\ \mathrm{C} & 0.000000 & -1.132588 & 2.545556 \\ \mathrm{H} & 0.000000 & -2.116650 & 3.001122 \\ \mathrm{C} & 0.000000 & 0.731197 & -1.196379 \\ \mathrm{C} & 0.000000 & 1.132588 & -2.545556 \\ \mathrm{H} & 0.000000 & 2.116650 & -3.001122 \\ \mathrm{C} & 0.000000 & -0.731197 & -1.196379 \\ \mathrm{C} & 0.000000 & -1.132588 & -2.545556 \\ \mathrm{H} & 0.000000 & -2.116650 & -3.001122\end{array}$

A-3

$\begin{array}{llll}\text { Atom } & \mathrm{x}[\AA] & \mathrm{y}[\AA] & \mathrm{z}[\AA] \\ \mathrm{C} & 0.000000 & 0.000000 & 3.305751 \\ \mathrm{~N} & 0.000000 & 1.379188 & 0.000000 \\ \mathrm{H} & 0.000000 & 0.000000 & 4.395519 \\ \mathrm{H} & 0.000000 & 2.395365 & 0.000000 \\ \mathrm{C} & 0.000000 & 0.000000 & -3.305751 \\ \mathrm{~N} & 0.000000 & -1.379188 & 0.000000 \\ \mathrm{H} & 0.000000 & 0.000000 & -4.395519 \\ \mathrm{H} & 0.000000 & -2.395365 & 0.000000 \\ \mathrm{C} & 0.000000 & 0.729656 & 1.188655 \\ \mathrm{C} & 0.000000 & 1.166540 & 2.516251 \\ \mathrm{H} & 0.000000 & 2.195173 & 2.866364 \\ \mathrm{C} & 0.000000 & -0.729656 & 1.188655 \\ \mathrm{C} & 0.000000 & -1.166540 & 2.516251 \\ \mathrm{H} & 0.000000 & -2.195173 & 2.866364 \\ \mathrm{C} & 0.000000 & 0.729656 & -1.188655\end{array}$




$\begin{array}{llll}\mathrm{C} & 0.000000 & 1.166540 & -2.516251 \\ \mathrm{H} & 0.000000 & 2.195173 & -2.866364 \\ \mathrm{C} & 0.000000 & -0.729656 & -1.188655 \\ \mathrm{C} & 0.000000 & -1.166540 & -2.516251 \\ \mathrm{H} & 0.000000 & -2.195173 & -2.866364\end{array}$

A-4

$\begin{array}{llll}\text { Atom } & \mathrm{x}[\AA] & \mathrm{y}[\AA] & \mathrm{z}[\AA] \\ \mathrm{C} & 0.000000 & -0.002206 & 3.312375 \\ \mathrm{C} & 0.000000 & 1.388779 & 0.033734 \\ \mathrm{H} & 0.000000 & 0.034094 & 4.399608 \\ \mathrm{H} & 0.000000 & 2.473933 & 0.106524 \\ \mathrm{C} & 0.000000 & 0.002206 & -3.312375 \\ \mathrm{C} & 0.000000 & -1.388779 & -0.033734 \\ \mathrm{H} & 0.000000 & -0.034094 & -4.399608 \\ \mathrm{H} & 0.000000 & -2.473933 & -0.106524 \\ \mathrm{~N} & 0.000000 & 0.684102 & 1.189734 \\ \mathrm{C} & 0.000000 & 1.120505 & 2.490675 \\ \mathrm{H} & 0.000000 & 2.180470 & 2.719927 \\ \mathrm{C} & 0.000000 & -0.735727 & 1.184546 \\ \mathrm{C} & 0.000000 & -1.157549 & 2.528885 \\ \mathrm{H} & 0.000000 & -2.189474 & 2.864533 \\ \mathrm{C} & 0.000000 & 0.735727 & -1.184546 \\ \mathrm{C} & 0.000000 & 1.157549 & -2.528885 \\ \mathrm{H} & 0.000000 & 2.189474 & -2.864533 \\ \mathrm{~N} & 0.000000 & -0.684102 & -1.189734 \\ \mathrm{C} & 0.000000 & -1.120505 & -2.490675 \\ \mathrm{H} & 0.000000 & -2.180470 & -2.719927\end{array}$




\section{References}

(s1) Nakano, M. Excitation Energies and Properties of Open-Shell Singlet Molecules: Applications to a New Class of Molecules for Nonlinear Optics and Singlet Fission; Springer: New York, 2014.

(s2) Minami, T.; Ito, S.; Nakano, M. Fundamental of Diradical-Character-Based Molecular Design for Singlet Fission. J. Phys. Chem. Lett. 2013, 4, 2133-2137.

(s3) Pradhan, E.; Lee, S.; Choi, C. H.; Zeng, T. Diboron- and Diaza-Doped Anthracenes and Phenanthrenes: Their Electronic Structures for Being Singlet Fission Chromophores. J. Phys. Chem. A 2020, 124, 8159-8172. 